\title{
The Physical Property Changes during Storage of 25-7-7 Analysis Grade of Suspension Fertilizer Processed by Luxen's Method
}

\author{
Pichai Triratanaprapunta ${ }^{1}$, Yongyuth Osotsapar ${ }^{2}$, Ravie Sethpakdee ${ }^{3} \&$ Suphachai Amkha $^{2}$ \\ ${ }^{1}$ Research and Development Program, Faculty of Agriculture at KamphaengSaen, Kasetsart University, Nakhon \\ Pathom 73140, Thailand \\ ${ }^{2}$ Department of Soil Science, Faculty of Agriculture at KamphaengSaen, Kasetsart University, Nakhon Pathom \\ 73140, Thailand \\ ${ }^{3}$ Department of Horticulture, Faculty of Agriculture at Kamphaeng Saen, Kasetsart, Nakhon Pathom 73140 , \\ Thailand
}

Correspondence: Suphachai Amkha, Department of Soil Science, Faculty of Agriculture at KamphaengSaen, Kasetsart University, Nakhon Pathom 73140, Thailand. E-mail: agrscak@ku.ac.th

Received: June 28, $2014 \quad$ Accepted: July 23, $2014 \quad$ Online Published: September 12, 2014

doi:10.5539/mas.v8n6p61 URL: http://dx.doi.org/10.5539/mas.v8n6p61

\begin{abstract}
The production of 25-7-7 analysis grade of suspension fertilizer processed by Luxen's Method was investigated for some physical properties changes during various storage periods. The solid instead of liquid raw materials were used in the production. The experiment was designed in CRD consisting of six storage treatments; $0,7,15$, 30, 90 and 180 days with 4 replicates. The total urea was provided for Urea 1 being fed in clear liquid mixed solution stage and Urea 2 being fed in suspended solution stage. The process was to add Urea 1, xanthan gum, $\mathrm{KCl}$, MKP, and Urea 2, respectively, into the cylindrical glass bottle which was mounted to the adjustable speeds of mixer and presented water. The resulting 25-7-7 analysis grade of suspension fertilizers were stored undisturbed at normal room temperature for various storage periods and its physical properties were analyzed periodically. The analysis of variance was performed using $\mathrm{R}$ statistical program. The result showed that $\mathrm{pH}$ of the suspension fertilizer ranged between 5.5-5.6 and specific gravity ranged 1.249-1.274 during all storage periods and there was nosignificant difference. The fertilizer viscosity increased as the storage times increased. The stability and the pour-ability were significantly decreased as the storage times increased. However, after six months, both stability and pour-ability were found to be above acceptable level. The changes in salting-out were found to be no significant difference among various storage periods. The result showed that the suspension fertilizers which were produced by Luxen's method could maintain their appropriate physical properties during six months of storage times.
\end{abstract}

Keywords: fertilizer, Luxen's Method, physical property, suspension, storage periods

\section{Introduction}

At present, most of the suspension fertilizer plants have used liquid raw materials: anhydrous $\mathrm{NH}_{3}(82 \% \mathrm{~N})$ and aqueous $\mathrm{NH}_{3}(20 \% \mathrm{~N})$ as sources of nitrogen; ortho phosphoric acid (wet process $55 \% \mathrm{P}_{2} \mathrm{O}_{5}$ ), super phosphoric acid (wet process $75 \% \mathrm{P}_{2} \mathrm{O}_{5}$ ) and solid ammonium phosphate (MAP: 12-60-0) as sources of phosphorous; $\mathrm{KCl}$ $\left(60 \% \mathrm{~K}_{2} \mathrm{O}\right)$ as source of potash. Sources of suspending agents used for the suspension fertilizer production method (Achorn \& Hargett, 1980) are clay, bentonite and gum. Thereby, the liquid starters for formulating suspension fertilizers, which are both NP base suspension fertilizers such as 8-24-0 (Wilbanks, 1967), 10-30-0 (Getsinger et. al., 1984), 9-32-0 (Mann et. al., 1983), 10-34-0, 12-40-0, 12-36-0 with ammonium lignosulfonate (Jones, 1978; Byrd \& Scott, 1979; Burnell \& Rylant, 1990) and UAN: 28-0-0, 30-0-0 and 32-0-0 (International Plant Nutrition Institute, 2012) are obtained. The other methods are simultaneous addition of fluorosilicic acid and suspending agents: clay for inhibiting large crystals of mono-ammoniun phosphate in the suspensions which were 12-12-12 (Mills, 1962), 14-14-14, 20-10-10 and 24-8-8 (Jones \& Stinson, 1983; Dillard \& Burnell, 1991), 11-39-0 (Wilbanks \& Faulkner, 1980). Some methods are comprised of the reaction product of urea, sulfuric acid and phosphoric acid for 20-20-0, 10-37-0, 5-45-0 (Stoller \& Hartung, 1982), 29-0-0-5S (TVA, 1985) and etc.

All production methods are in conventional suspension fertilizer plants that based on hot mix plant which is the 
TVA three-stage continuous ammoniation. The acid is ammoniated in three stages, with precise temperature and $\mathrm{pH}$ control in each stage (Jones \& Getsinger, 1979). When the ortho phosphoric acids are being fed into the tank reactor (also pipe reactor) by the connecting pipes, immediately, anhydrous $\mathrm{NH}_{3}$ and potassium are being fed into them by the other connecting pipes also. The reaction would occur with high temperature which is more than $750{ }^{\circ} \mathrm{C}$ and certainly with high pressure. Thereby, it caused the risk of a massive explosion at the fertilizer plant that killed as many as 15 people and injured more than 160 in April 2013, in West, Texas. The explosion left large damaged areas and more than 150 damaged buildings. The disaster was not the first time but was the sixtieth time since 1953 (Mungin, 2013).

Moreover, the conventional plants are extensively complicated the handling of liquid raw materials. This is because of the use of many tanks and cooling tower complicates the production of UAN solutions because of potential explosive raw material such as ammonium nitrate. Such raw material is very difficult in seeking permit from the Ministry of Defense for the importation into Thailand as well as its high investment cost of corrosive maintenance.

The main objective of this research is to improve the suspension fertilizer production method using solid instead of liquid raw materials. Xanthan gum is being used as raw material in suspension fertilizer production for obtaining appropriate suspension fertilizers in both chemical and physical properties.

\section{Methods}

In a number of unpublished preliminary investigations, the results showed that Luxen'smethod was significantly effective in the suspension fertilizer production. This could be attributed to following 4 factors;1) milled raw materials in particle size of more than 20 meshes, 2) appropriate speeds of agitator: $1280 \mathrm{rpm}$ for clear liquid mixed solution stage and 2620rpm for suspended solution stage, 3) appropriate solution temperature of 30 to $40^{\circ} \mathrm{C}$, and 4) xanthan gum .suspension agent of $2.5 \%$

Luxen's method was also used in present studies for the production of 25-7-7 analysis grades of suspension fertilizers .The experiment consisted of 6 storing factor periods of $0,7,15,30,90$, and 180 days using CRD experimentaldesign with 4 replicates. The process was to add $72.1 \mathrm{~g}$ Urea 1 in clear liquid mixed solution stage with $1280 \mathrm{rpm}$ speed, simultaneously, $5.5 \mathrm{~g}$ xanthan gum, $9.1 \mathrm{~g} \mathrm{KCl}, 29.7 \mathrm{~g}$ MKP and $47.5 \mathrm{~g}$ Urea 2 in suspended solution stage with $2620 \mathrm{rpm}$ speed, respectively, into the bottle which was mounted to the adjustable speeds of mixer and presented $56.1 \mathrm{~g}$ water (Table 1).

Table 1. Treatments, amounts of solid raw materials, storage periods for 25-7-7 analysis grade of suspension fertilizer

\begin{tabular}{llllllllllll}
\hline \multicolumn{4}{c}{ Amount of solid raw materials (gram) } & \multicolumn{5}{c}{ Storage periods (day) } \\
\hline water & U 1 & gum & KCl & MKP & U 2 & 0 & 7 & 15 & 30 & 90 & 180 \\
\hline 56.1 & 72.1 & 5.5 & 9.1 & 29.7 & 47.5 & Tr1 & Tr2 & Tr3 & Tr4 & $\operatorname{Tr} 5$ & $\operatorname{Tr} 6$ \\
\hline
\end{tabular}

Note: $\mathrm{U}=$ milled urea, gum $=$ xanthan gum, $\mathrm{KCl}=$ potassium chloride, $\mathrm{MKP}=$ mono potassium phosphate.

The suspensions were agitated for homogenization. The resulting 25-7-7 suspensions were stored undisturbed for various storing time periods at normal room temperature. The suspensions were then evaluated for the changes of physical properties using various equipments and calculations as follows: 1) the $\mathrm{pH}$ using portable $\mathrm{pH}$ meter, Checker ${ }^{\circledR}$ from USA, 2) specific gravity using specific gravity hydrometer, 3) stability using calculation of amounts of clear liquid (supernatant) on the top of the suspension fertilizer in a graduate cylinder after standing undisturbed for 24 hours (Browder \& Ulmer, 1971), 4) pour-ability using calculation of amounts of the poured products and the remained products which were poured from the bottle after standing undisturbed for 24 hours (CIPAC 2009; Salladay \& Kachelman, 1986), 5) viscosity using detecting with Brookfield digital viscometer (CIPAC 2009a; Davenport et. al., 1978), and 6) salting out using calculation of amounts of retained crystals of the product on the 20 mesh standard test sieve (CIPAC 2009b; Byrd \& Scott, 1979). Analysis of variance was performed in $\mathrm{R}$ program for all raw data.

\section{Results and Discussion}

The results showed that all of 6 treatments of storing time periods were found to be non-caking, homogenized, suspended fertilizers. The suspensions were of xanthan gum suspended consisting of needle crystals in Urea 1 which were $100 \mu \mathrm{m}$ width and 2,000 $\mu \mathrm{m}$ length, suspended $\mathrm{KCl}$, suspended MKP and suspended Urea 2, (Figure 


\section{1, 2, 3 and 4).}

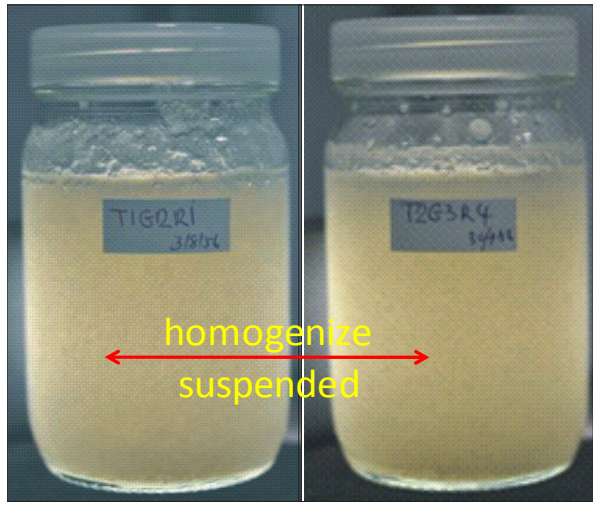

Figure 1. non-caking, homogenized and suspended fertilizers

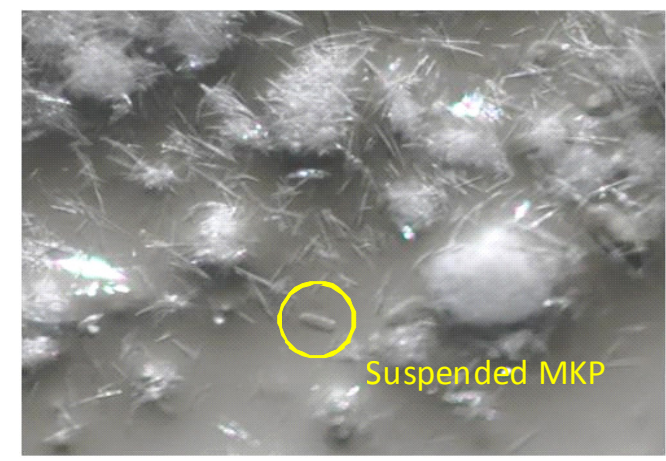

Figure 3. $\mathrm{m}$ agnified picture of the composition of 25-7-7 suspension fertilizer

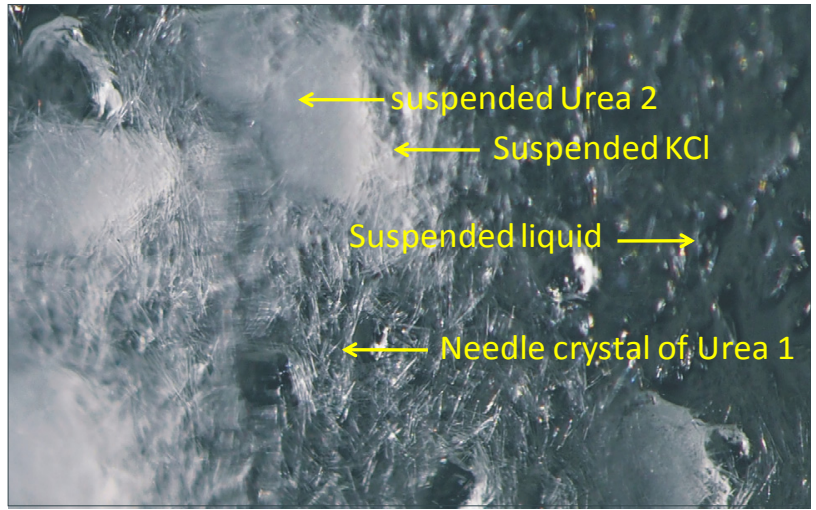

Figure 2. the magnified picuture of the composition of 25-7-7 suspension fertilizer

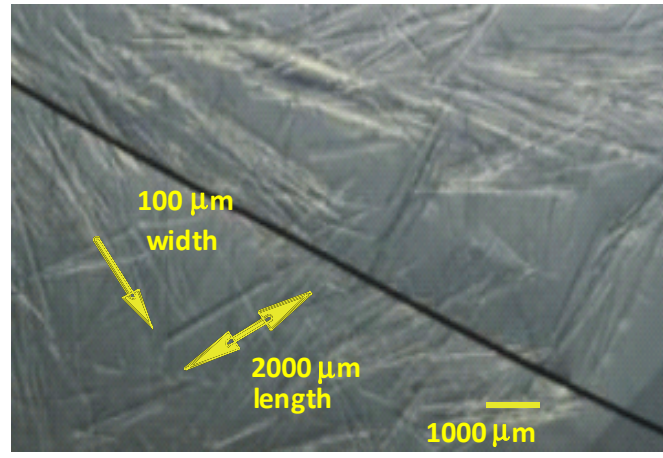

Figure 4. measured needle crystals of Urea 1 fron 25-7-7 suspension fertilizer

It could be described that $72.1 \mathrm{~g}$ Urea 1 were completely dissolved in $61.6 \mathrm{~g}$ water treated by the temperatures of $30^{\circ} \mathrm{C}$ to $40^{\circ} \mathrm{C}$ in the first stage. By then, the solutions had become saturated solutions. The suspending agent: 5.5 $\mathrm{g}$ xanthan gum was fed into those solutions and the viscosity of solutions was affected [3 dimension networks of xanthan gum solution (Figure 5) with suspension properties (Wolf et. al., 1985). Further addition of $9.1 \mathrm{~g} \mathrm{KCl}$, $29.7 \mathrm{~g}$ MKP and $47.5 \mathrm{~g}$ Urea 2 were fed into the saturated suspension solutions in the second stage, respectively. All of them could be completely dissolved little by little and the remaining parts were non-dissolved which were held up (they were attracted to xanthan gum by van der Waals force, Figure 5) by xanthan gum in the saturated suspension solutions. At the same time, the saturated suspension solutions had become the super saturated suspension solutions. Crystallization of Urea 1 crystals by large number of molecular formation was observed in that suspensions and these molecular crystals were formed by van der Waals force: Cohesive force (Chemistry.s.c.chula, 2012). According to the super saturated suspension solutions which had suspension property, Urea 1 molecules and the crystals of Urea 1 were surrounded by xanthan gum (they were also attracted to xanthan gum by van der Waals force in 3 dimension networks of xanthan gum solution, Figure 5). They couldn't lump together. The formation of the gelatinous molecules of Urea 1 in form of long crystals (large crystal growth) were limited affecting the formation of the more shorten (needle) crystals of Urea 1 (100 $\mu \mathrm{m}$ width and $2000 \mu \mathrm{m}$ length in needle crystals of Urea 1 as Figure 4) in the suspended solution instead. The suspensions were homogenized and suspended with no sediment and no caking (Figure 1). This pathway was in line with that of Mier's theory (Khanam, 2007), van der Waals force and suspension property of Xanthan gum. This research result was similar to the previous researches which were found that the suspension fertilizers must be consisted of suspending agents: attapulgite, sepiolite, sodium bentonite and polysaccharides (Makower \& Kohn, 1962; Fox \& Oldland, 1976; Salladay et. al., 1984; Colegrove, 1984; Wolf et. al., 1985; Fraley \& Rogers, 1997). 


\subsection{Structure of Suspension Fertilizer}

The structure of 25-7-7 analysis grade of suspension fertilizer (Figure 3) was found to be consisted of water, xanthan gum, non-dissolved raw materials (Urea 2, MKP and $\mathrm{KCl}$ ) and needle crystals of Urea 1. All of the materials were linked together with various attractive forces as the proposed structure in Figure 3. After the feeding of Xanthan gum into the Urea 1 solution in clear liquid mixed solution stage (the first stage), the linkage with water molecules were formed in the solution with hydrogen bond. The formation of 3 dimension networks of xanthan gum solution occurred with 5 types of attraction forces. At the finished process, the bond formations were going to occur, simultaneously. Each xanthan gum portion could be previously cross- linked together each by covalent bond (at C1-C4 of $\beta$-D-glucose 2 molecules) in 3 positions in forming big agglomerate (Anil. 2012). Water molecules could be attracted to xanthan gum by hydrogen bonds for the formation of 3 dimension networks of xanthan gum solution which were deranged (entanglement). The 4 carboxyl groups on xanthan gum could be attracted by each xanthan gum and some non-dissolved raw materials. The non-dissolved raw materials could be attracted among them by Intermolecular force and many hydroxyl groups on xanthan gum could be attracted by some non-dissolved raw materials (NQF-AGRO, 2001; Aimtrakarn et al., 2011). All of these attraction forces, van der Waals force with weakly cross-linked forces, had affected on viscosity and suspended solution suspended the non-dissolved raw materials for non-sedimentation. All of 6 treatments in this research were significantly different inthe physical properties except $\mathrm{pH}$ and specific gravity (Table 2).

Table 2. The physical properties of 25-7-7 analysis grade of suspension fertilizer during storage periods

\begin{tabular}{lllllll}
\hline \multicolumn{7}{c}{ Physical property } \\
Storage time & $\mathrm{pH}$ & S.G. & $\begin{array}{l}\text { Viscosity } \\
\left(\mathrm{mPa}^{1 /}\right)\end{array}$ & $\begin{array}{l}\text { Stability } \\
\left(\%{ }^{2 /}\right)\end{array}$ & $\begin{array}{l}\text { Pour-ability } \\
\left(\%^{3 /}\right)\end{array}$ & $\begin{array}{l}\text { Salting out } \\
\left(\%{ }^{4 /}\right)\end{array}$ \\
\hline $\operatorname{Tr} 1(0 \mathrm{~d})$ & 5.6 & 1.263 & $1445 \mathrm{~d}^{5 /}$ & $100.0 \mathrm{a}^{5 /}$ & $3.19 \mathrm{c}^{5 /}$ & 0 \\
$\operatorname{Tr} 2(7 \mathrm{~d})$ & 5.5 & 1.274 & $1887 \mathrm{~d}$ & $100.0 \mathrm{a}$ & $3.29 \mathrm{c}$ & 0 \\
$\operatorname{Tr} 3(15 \mathrm{~d})$ & 5.5 & 1.252 & $2832 \mathrm{c}$ & $99.62 \mathrm{~b}$ & $4.09 \mathrm{~b}$ & 0 \\
$\operatorname{Tr} 4(30 \mathrm{~d})$ & 5.6 & 1.267 & $3196 \mathrm{c}$ & $98.75 \mathrm{c}$ & $4.50 \mathrm{ab}$ & 0 \\
$\operatorname{Tr} 5(90 \mathrm{~d})$ & 5.5 & 1.257 & $15195 \mathrm{~b}$ & $98.66 \mathrm{~cd}$ & $4.71 \mathrm{ab}$ & 0 \\
$\operatorname{Tr} 6(180 \mathrm{~d})$ & 5.5 & 1.249 & $16361 \mathrm{a}$ & $98.54 \mathrm{~d}$ & $4.97 \mathrm{a}$ & 0 \\
F-Test & $\mathrm{ns}$ & $\mathrm{ns}$ & $*$ & $*$ & $*$ & $\mathrm{~ns}$ \\
C.V. $(\%)$ & 2.3 & 1.1 & 6.2 & 0.15 & 10.2 & \\
\hline
\end{tabular}

Note: $\mathrm{SG}=$ specific gravity.

${ }^{1 /}$ by Brook field viscometer, spindle \# 3 and 4, $30 \mathrm{rpm}$, time 2 minute.

${ }^{2 /} \%$ of the apparent solids.

${ }^{3 /} \%$ of the remaining products.

${ }^{4 /} \%$ of the retained crystals on the 20 mesh screen of test sieve.

${ }^{5 /}$ Means in a column followed by the same letter are not significantly different.

* significantly different, $\mathrm{ns}=$ non-significantly different, according to $\operatorname{LSD}(P<0.05)$.

\section{2 $\mathrm{pH}$ and Specific Gravity (SG)}

From Table 2, the $\mathrm{pH}$ and specific gravity properties among all 6 treatments showed non-significantly difference varying from 5.5 to 5.6 and 1.249 to 1.274 , respectively. It indicated that all of storage periods did not affect on $\mathrm{pH}$ and specific gravity of the suspensions because there was no chemical reaction of the solid raw materials in the process and the same rates of raw materials in their components which affected on the same total amount of Hydrogen ion: $\mathrm{H}^{+}$in the suspensions. Furthermore, for this new suspension fertilizer production method, the so many high as $\mathrm{pH}$ of the products were not major appropriateness like as a $\mathrm{pH}$ of 25-7-7 analysis grade of suspension fertilizer being imported by Captain Fertilizer Co., Ltd. was 7.2 which was evaluated by Department of agriculture (Captain Fertilizers, 2012), and the previous researches of Kendrick (1974) found that the pH of suspension fertilizers were more than $\mathrm{pH} 5.9$ which affected on more crystals of DAP, less than $\mathrm{pH} 5.9$ which affected on more MAP which could grow up in large crystals. Miller (1962) found that the proper $\mathrm{pH}$ of the 
appropriate suspension fertilizers varied from 7.5 to 8 , the more than $\mathrm{pH} 8$ affected on decreased solubility of nutrients and tended to salting out. The new production method had no chemical reaction of solid raw materials in process similar to that produced by conventional method. However, it involved in solubility of raw materials and property of suspending agent: xanthan gum. The $\mathrm{pH}$ of 5.5 to 5.6 of the products was compatible to other agricultural chemicals. The specific gravity's measurements had indicated many things about the relative compositions of fluid fertilizers when correlated with other data for the particular solution or suspension. They are commonly made at $25^{\circ} \mathrm{C}$ and are useful in adjusting the calibrated application equipment to obtain accurate application rates for the particular fluid fertilizers (Wolf et. al., 1985). The 25-7-7 analysis grade of suspension fertilizers in this research had specific gravities of 1.249 to 1.274 in compare with that imported by Captain Fertilizer Co., Ltd. with 1.29 which was evaluated by the Department of Agriculture (Captain Fertilizers, 2012).

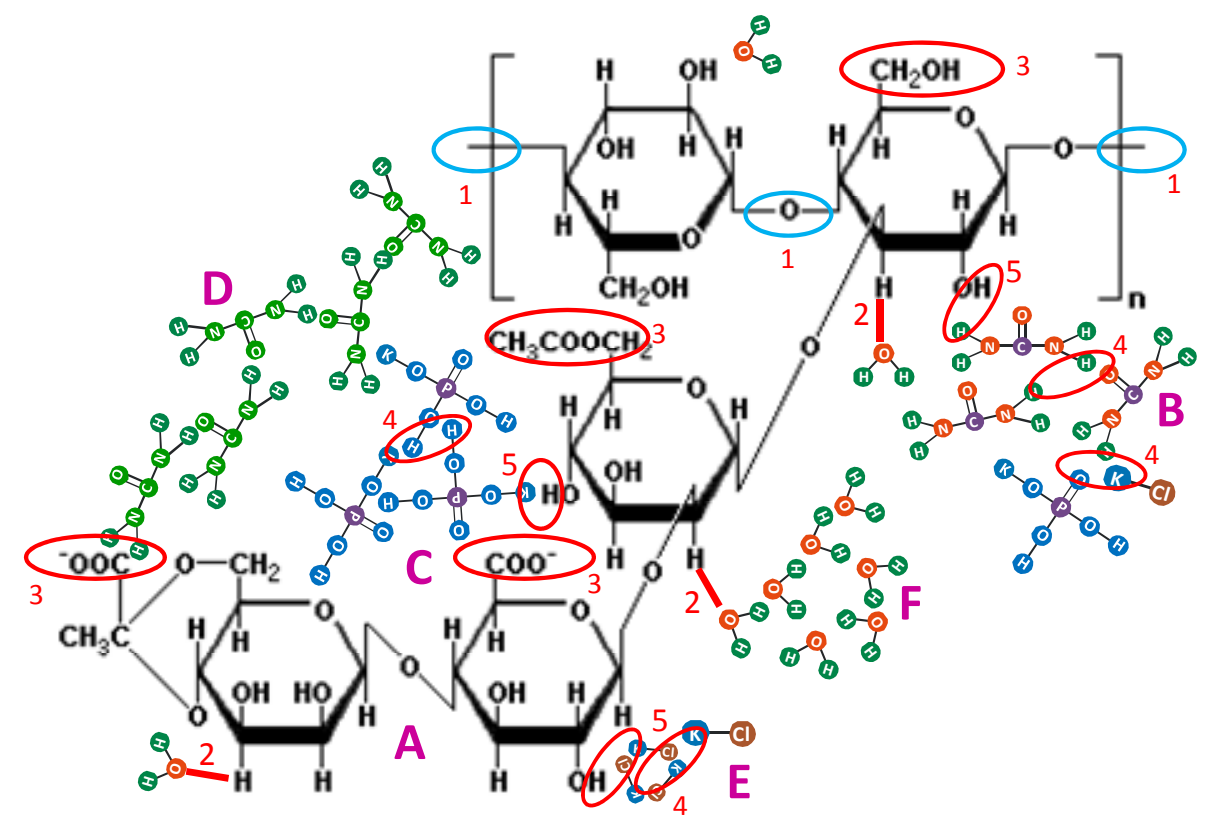

Figure 5 Structure of suspension fertilizer, linkage among xanthan gum, $\mathrm{H} 2 \mathrm{O}$, non-dissolved raw materials:

Urea 2, $\mathrm{KH} 2 \mathrm{PO} 4$ and $\mathrm{KCl}$ and needle crystals of Urea $1, \mathrm{~A}=$ xanthan gum, $\mathrm{B}=$ Urea 2,

$\mathrm{C}=\mathrm{KH} 2 \mathrm{PO} 4, \mathrm{D}=$ needle crystals of Urea1, $\mathrm{E}=\mathrm{KCl}, \mathrm{F}=\mathrm{H} 2 \mathrm{O}, 1=$ covalent bond, van der Waals

force: 2 = hydrogen bond, 3 = carboxyl group, 4 = intermolecular force, 5 = hydroxyl group

\subsection{Viscosities}

All of 6 treatments, storing periods, there was a significant difference among various viscosities that varied from 1445 to $16361 \mathrm{mPa}$.s (Table 2). The results showed that the suspensions stored within 7 days gave the lowest viscosity, $1887 \mathrm{mPa}$.s, the suspensions stored at interval between 15-30 days gave medium viscosity, $3196 \mathrm{mPa} . \mathrm{s}$ and the suspensions stored at interval between 90-180 days showed high viscosity of $16361 \mathrm{~m} \mathrm{Pa.s.} \mathrm{It} \mathrm{could} \mathrm{be}$ noticeable that increasing stored periods affected on increasing viscosities. These were illustrated by structure of suspension fertilizer in Figure 5.

\subsection{Structure of Suspension Fertilizer}

In 25-7-7 analysis grade of suspension fertilizer (Figure 5), they were consisted of water, xanthan gum, non-dissolved raw materials (Urea 2, MKP and $\mathrm{KCl}$ ) and needle crystals of Urea 1. All of them linked together with variously attractive forces. After the Xanthan gums were fed into the Urea 1 solution in clear liquid mixed solution stage, they linked to water molecules in the solution with hydrogen bond to form in 3 dimension networks of xanthan gum solution. As processing, the suspensions consising of xanthan gums, dissolved and non-dissolved raw materials were being agitated. The chains of polymer could not form in high three dimensional networks immediately. They were ordered arrangement which affected on low physical forces (intermolecular force, Van der Waals force and hydrogen bond) in the suspensions. Therefore, the measured 
viscosities by Brookfield Viscometer at initial time were low. When the suspensions were stored (the agitating removed) at various periods, $0,7,15,30,90$ and 180 days, the bond formations were going to occur in xanthan gum solution. More physical forces among them affected on formation of big agglomerates (high entanglement density) of three dimensional networks which were deranged because the suspensions were non-Newtonian fluids and pseudo-plastic fluid which affected on Thixotropic Flow Behavior (Aimtrakarn et al., 2011). So the high entanglement density of xanthan gum polymer was depended on the increasing storage periods (Thixotropic Flow Behavior) which was in line with the research of Sawyer, Jr (1991) who found that viscosity increased along the increasing storage time. The stored periods affected on both high viscosity and suspended solution which suspended the non-dissolved raw materials for non-sediment. So the measured viscosities at variously given periods were high and in line with the research of Sawyer (1991) who found that treated suspension fertilizer by some shear stress could reduce viscosity to a low level. Aimtrakarn et al. (2011) also noted that in Thixotropic Flow Behavior, it took more times to reversion of big agglomerates by random Brownian movement. Therefore, the measured viscosity was detected by using more shear rates in Brookfield viscometer which affected on high viscosity because of all of the attractive forces being destroyed by the more shear rates. In this investigation, it was found that the storing period within 7 days was the appropriate treatment because the viscosities of 1445 and $1887 \mathrm{mPa}$.s could be obtained and in line with the research of Salladay \& Kachelman (1986) who found that viscosity was depended on analysis grade of suspension fertilizers and concentrations of suspending agent, which were 100-2000 mPa.s in appropriate limits.

\subsection{Stability}

All of 6 treatments gave 98.54 to 100\% apparent solids at various storage periods (Table 2) and showed significantly different. The apparent solids of $100 \%$ indicated that there was no any volume of clear liquid on the top of the suspension ( $0 \%$ supernatant) but the $98.54 \%$ apparent solids could contain $1.46 \%$ supernatant. This investigation found that the storing period of $0,7,15,30,90$, and 180 days gave the stability of apparent solid of $100 \%$ ( $0 \%$ supernatant), $100 \%$ ( $0 \%$ supernatant), $99.62 \%$ ( $0.38 \%$ supernatant), $98.75 \%$ ( $1.25 \%$ supernatant), $98.66 \%$ (1.34\% supernatant) and $98.54 \%$ (1.46\% supernatant), respectively. It could be noticeable that long stored periods affected on low \% apparent solids of suspensions (high \% supernatant). The results were comparable to the acceptable limits of stability in that the suspensions stored within 7 days showed excellent stability. Furthermore, the suspensions stored at interval between 15-180 days gave very good stability (Browder \& Ulmer, 1971). These were described by structure of suspension fertilizer in Figure 5.

From Figure 5 , there were 5 types of attraction forces $(1=$ covalent bond, van der Waals force: 2 = hydrogen bond, 3 = carboxyl group, $4=$ intermolecular force, 5 =hydroxyl group) in the structure of suspension fertilizer. All of components were weakly cross linked among them by those attraction forces in the suspension. According to gravitational force and long storage period, the finished products being stored undisturbed for various long periods, the hydrogen bonds (Figure 5) which cross linked between water molecules and xanthan gums were destroyed by gravitational forces. The separated water molecules floated on the top of the suspensions. The longer storage periods resulted in obtaining more separated water molecules and more clear liquids observed at the top of suspension. Moreover, the unpublished preliminary investigation in suspending agents, the results showed the suitable concentration of suspending agents would affect on the appropriate supernatant in suspensions. The research of Sawyer Jr (1991) who found that the shrinkage of gel and insufficient of suspending agents affected on supernatant in the suspension.

\subsection{Pour-Ability}

All 6 treatments in Table 2 showed significant difference in pour-ability, varying from 3.19 to $4.97 \%$ of the remaining products. The average of the remaining products was $4.13 \%$. This investigation found that the storing periods of $0,7,15,30,90$, and 180 days gave pour-ability of $3.19 \%, 3.29 \%, 4.09 \%, 4.50 \%, 4.71 \%$, and $4.97 \%$, respectively. It resulted in affecting on low pour-ability of suspensions (high \% the remaining products). The suspensions with high treated Xanthan gums were clearly difficult in pouring because of its high viscous liquids (high viscosity). So, more products were always stuck on the wall of the bottle which affects on the more $\%$ the remaining products. The results were comparable to acceptable limits of pour-ability of not more than $5 \%$ of the remaining products (CIPAC MT 148, 2009; Salladay and Kachelman, 1986). These could be described by the structure of suspension fertilizer shown in Figure 5.

Figure 5 showed that there were 5 types of attraction forces $(1=$ covalent bond, van der Waals force: $2=$ hydrogen bond, 3 = carboxyl group, $4=$ intermolecular force, $5=$ hydroxyl group) in the structure of suspension fertilizer. All of components were weakly cross linked among them by those attraction forces in the suspension. The suspension fertilizer was non-Newtonian fluid and pseudo-plastic fluid type (Aimtrakarn et al., 2011) which 
affect on thixotropic behavior in suspension. As the suspensions being agitated in the suspended solution stage, they exhibited low viscosities because of 3 dimension networks of xanthan gum solution being ranged (low entanglement density of xanthan gum polymer). Then, at the finished process (the agitating removed), the bond formations being occurred, it took more times to rebuild high 3-dimension networks (big agglomerates or high entanglement density) like as recovery in thixotropic behavior in suspension. Therefore, the high pour-ability (low \% the remaining products) being evaluated at initial time was received. These were in line with the research of Sawyer (1991) who found that a treated suspension fertilizer by some shear stress affected on being reduced viscosity to low one and Aimtrakarn et al., (2011) who noted that in Thixotropic Flow Behavior, it took more times to reversion of big agglomerates by random Brownian movement. The high employment in treated Xanthan gums which were employed in suspension fertilizers affected on high entanglement density of xanthan gum polymer (high 3 dimension network) and high viscosity because of cross linkage between the xanthan gums and the components in suspensions by more van der Waals forces (Figure 5). These researches were related to 24-8-8 grade of suspension which was made from liquid raw materials: $12-38-0, \mathrm{UAN}(32 \% \mathrm{~N}), \mathrm{KCl}, 1 \%$ clay, $0.3 \% \mathrm{H}_{2} \mathrm{SiF}_{6}$ gave low viscosity: $300-800 \mathrm{cps}$ which affected on high pour-ability ( $0 \%$ the remaining products) (Jones \& Stinson, 1983).

\subsection{Salting Out}

All of treatments in Table 2 gave $0 \%$ retained crystal on the 20 mesh screen sieve, which were non-significantly different. The $0 \%$ salting out meant there were no any retained crystals on 20 mesh screen of the test sieve. All treatments were appropriate suspensions that could be compared with the acceptable limits: maximum $2 \%$ retained crystals on a 20 mesh sieve (CIPAC, 2009b; Byrd \& Scott, 1979). They were described that all of treatments were treated by Luxen's method that were the temperature of solution: 30 to $40^{\circ} \mathrm{C}$, the milled raw materials in particle size of more than 20 meshes, and the suspending agent: $2.5 \%$ xanthan gum. That temperature: 30 to $40^{\circ} \mathrm{C}$ affected on the small crystals of nutrient materials in suspension which related to many researches of Slack \& Walters (1963); Kendrick (1974); Fox \& Oldland (1976) who found that the temperature of solution $29^{\circ} \mathrm{C}, 38^{\circ} \mathrm{C}$ and 70 to $82^{\circ} \mathrm{C}$ affected on the small crystals of nutrient materials in the suspension fertilizers, respectively.Furthermore, Johnson \& Huber (1991) who found that a suspension with sufficient gel strength would support the solids contained in the suspension preventing them from setting out. So the suitable suspending agent found in this research was $2.5 \%$ xanthan gum in the suspensions which gave $0 \%$ retained crystal on the 20 mesh screen sieve at various storage periods. The particle size of raw materials contributes to less salting out. In these researches, more than 20 meshes milled raw materials were enough to be employed in the process which affected on $0 \%$ retained crystal on the 20 mesh screen sieve. They were related to Sawyer (1991); Aijala \& Ahlnas (1998) who found that the appropriate particle size of raw materials were 35 meshes and 18-140 meshes, respectively, that affected on the less salting out. Moreover, the particle size of milled raw materials which was more than 20 meshes and could be trapped by hollows of 3 dimension network of xanthan gum solution (NQF-AGRO, 2001; Aimtrakarn et al., 2011) affected on less than weakly intermolecular force which were the electrostatic attraction, van der Waals force and hydrogen bond. The large particle size affects on more strongly intermolecular force than small particle size (Sirimungkala, 2012; Anuragudom, 2012). Chance of formation in large agglomerates from the non-dissolved raw materials is less because of less than weakly intermolecular force in them. Nevertheless, the raw material composition of $25-7-7$ at 30 to $40^{\circ} \mathrm{C}$ in these researches, which was $54.3 \%$ urea, $4.13 \% \mathrm{KCl}$ and $13.5 \% \mathrm{MKP}$ were related to the raw material composition of 21-7-7 at $29^{\circ} \mathrm{C}$ which was not greater than in each of $57.6 \%$ urea, $28.3 \% \mathrm{KCl}, 21.1 \% \mathrm{MKP}$ respectively, which non-affecting on salting out (Wolf et. al., 1985) and 24-8-8 grade of suspension which was made from liquid raw materials: APP (12-38-0), UAN (32\% N), KCl, 1\% clay, 0.3\% H2SiF6 gave low viscosity: 300-800 mPa.s which affected on $0 \%$ salting out (Jones \& Stinson, 1983).

\section{Conclusion}

The 25-7-7 analysis grade of suspension fertilizers processed by Luxen's method was a non-Newtonian fluid, pseudoplastic fluid type, thixotropy, $\mathrm{pH}$ : 5.6, and specific gravity: 1.274. The storage periods affected on viscosity that increased along with increasing storage periods. They also affected on very good to excellent stability and acceptation in both pour-ability and salting out. Thereby, they had high efficiency in physical properties within 180 days of storage time period at normal room temperature.

\section{References}

Achorn, F. P., \& Hargett, N. L. (1980). Recent Fluid Fertilizer Trends. Am. Chem. Soc., Las Vegas, Nev., Aug. 24-29.

Aijala, H., \& Ahlnas, T. (1998). Suspension fertilizer suitable for irrigation fertilization and a process for its 
preparation US.Patent 5,851,260.

Aimtrakarn, S., Ratiya, K., Peeranuchna, C., Kainapa, V., \& Sopapun K. (2011). Rheology, Basic Principle in Pharmaceutical Technology, Faculty of Pharmaceutical Sciences, KhonKaen University, KhonKaen, Thailand. $\quad$ Retrieved May 15, 2013, from http://pharm.kku.ac.th/thaiv/depart/techno/basicpharm/downloads/Lesson4.pdf

Anil L. (2012). Xanthan - A Versatile Gum, general article. Division of Biochemical Sciences of National Chemical Laboratory, Pune. Retrieved May 16, 2012, from http://www.ias.ac.in/resonance/Volumes/09/10/0025-0033.pdf

Anuragudom P. (2012). Intermolecular Forces. Retrieved July 26, 2012, from http://chem.flas.kps.ku.ac.th/SLIDE/SLIDE-01403312-53-molecular-force.pdf

Browder, L. E., \& Ulmer, H. E. (1971). Method for Producing Aqueous Suspension Fertilizer. US. Patent 3582311.

Burnell, J. R., \& Rylant, W. K. (1990). Batch production of suspension fertilizers using lignosulfonate. US Patent 4,932,993.

Byrd, M. D., \& Scott, A. R. (1979). Method of Preparing Liquid Monoammonium Phosphate Fertilizer Suspension.US.Patent 4133670.

Captain Fertilizers. (2012). Recommendation for suspension fertilizers: 25-7-7, captain fertilizer Co., Ltd., Bangkok.

Chemistry.s.c.chula. (2012). Van der Waals forces. Retrieved May 15, 2012, from www.chemistry.sc.chula.ac.th/course_info/.../charpter_1_update.ppt

CIPAC (2009a). Viscosity of Liquids by Rotational Viscometry, The CIPAC Handbooks. Collaborative International Pesticide Analytical Council (CIPAC) methods, Black Bear press, Kings Hedges Road, Cambridge, U.K.

CIPAC (2009b). Wet Sieve Test, The CIPAC Handbooks. Collaborative International Pesticide Analytical Council (CIPAC) methods, Black Bear press, Kings Hedges Road, Cambridge, U.K.

CIPAC. (2009). Pour ability of Suspension Concentrations. The CIPAC Handbooks, Collaborative International Pesticide Analytical Council (CIPAC) methods, Black Bear press, Kings Hedges Road, Cambridge, U.K.

Colegrove, G. T. (1984). Polysaccharide suspending agents for fertilizers containing Paraquat Paper presented at American Chemical Society National Meeting, Philadelphia, PA, Aug 26-31, 1984.

Davenport, J. E., Getsinger, D. W., Rindt, D. W., \& Nichols, D. E. (1978). Suspension fertilizers: gel strength measurement and gel characteristics studied. Solutions, 22, 92-99.

Dillard, E. F., \& Burnell, J. R. (1991). Stabilized ammonium orthophosphate suspensions.US.Patent 5,022.913.

Fox, R., \& Oldland, H. C. (1976). Products and Processes, US.Patent 3,950,159.

Fraley, R. W., \& Rogers, P. (1997). Pestidal Micronutrient Compositions Containing Zinc Oxide.US. Patent 5, 667,795 .

Getsinger, J. G., Achorn, F. P., \& Hoffmeister, G. (1984). Suspension fertilizers production and use. Chapter 7 in Fluid Fertilizers, Potts, J. M., eds, TVA, National Fertilizer Development Center, Muscle Shoals, Al. TVA Bulletin Y-185.

International Plant Nutrition Institute. (2012). urea-ammonium nitrate, Nutrient Source Specifics. International Plant Nutrition Institute, Georgia 30092-2844 US. Retrieved August 20, 2012, from http://www. ipni.net

Johnson, F. J., \& Huber, E. J. (1991). Quality of Fluid Fertilizers, pp. 537-543. In Palgrave, D. A. (Eds.), Fluid Fertilizer, science and Technology, Marcel Dekker, Inc., New York, Basel, Hong Kong.

Jones, M. M., \& Stinson, J. M. (1983). Production of suspension fertilizers from orthophosphoric acid. US. Patent 4,375,980.

Jones, T. M. (1978). Production of suspension fertilizers from wet-process orthophosphoric acids. US. Patent $4,066,432$.

Jones, T. M., \& Getsinger, J. G. (1979). High grade suspensions produced from wet-process ortho-phosphoric acid, Fertilizer Solutions, 23, 68.

Kendrick, L. A. (1974). Production of Suspension Fertilizers from Wet-Process Orthophosphoric Acids.US. 
Patent 3,813,233.

Khanam, J. (2007). Crystallization, Pharmaceutical Engineering,Pharmaceutical Engineering Division, Department of Pharmaceutical Technology, Jadavpur University, Kolkatta-700032. Retrieved January 25, 2013, from http://nsdl.niscair.res.in/bitstream/123456789/598/1/corrected+crystallization.pdf

Makower, B., \& Gustave, K. K. (1962). Stabilized Plant Nutrient Composition. US Patent 3,041,160.

Mann, H. C., McGill, K. E., \& Achorn, F. P. (1983). Producing 9-32-0. Solutions 27, 53-61, $63-64$.

Miller, R. C. (1962). Method of preparing a stable liquid fertilizer from wet-process phosphoric acid. US.Patent 3,022,153.

Mills, H. E. (1962). Fertilizer Solutions, 6(6), 38

Mungin L. (2013). Explosion hits fertilizer plant north of Waco, Texas, CNN. Retrieved December 20, 2013, from www.cnn.com/2013/04/17/us/texas-explosion/

NQF-AGRO. (2001). Colloidal System in Foods, A Network for the Development of National.

Qualifications Framework (NQF). For Agro-Industry Field in Thailand. Retrieved July 20, 2001, from http://nqf.agro.ku.ac.th/UP/e-courseware/eakapan/lesson1/collide1.html

Salladay, D. G., \& Kachelman, D. L. (1986). Sodium bentonite-UAN suspension without chemical dispersants, US.Patent 4617048.

Salladay, D. G., Kachelman, D. L., \& Cuafield, R. B. (1984). The use of sodium bentonite as a suspending agent in fluid fertilizers, Paper presented at American Chemical Society National Meeting, Philadelphia, PA, Aug 26-31, 1984.

Sawyer, E. W. (1991). Physical and Chemical Phenomena Controlling the Stability and Flow Property in Suspensions. In P algrave, D. A. (Ed.), Fluid Fertilizer, Science and Technology (pp. 121-140). Marcel Dekker, Inc., New York, Basel, Hong Kong.

Sirimungkala, A. (2012). Liquid and Solution. Retrieved March 15, 2012, from http://chemsci.kku.ac.th/atchara/Slide/313101/313101-2.pps

Slack, A. V., \& Walters, H. K. (1963). METHOD OF PRODUCING HIGH-ANALYSIS FERTILIZER SUSPENSIONS.US.Patent 3,113,858.

Stoller, J. H., \&Hartung H. A. (1982). High analysis liquid fertilizers, US.Patent 4,315,763

TVA. (1985). Urea ammonium sulfate (UAS) suspension fertilizer, Tennessee Valley Authority. Nitrogen, 153, 20-31.

Wilbanks, J. A. (1967). Suspensions and Slurries, Agric. Chem. 22, 37.

Wilbanks, J. A., \& Faulkner, L. C. (1980). New Suspension Products and Processes under Development By TVA, pp 130-142. In A. Spillmaneds Proceedings of the 30th Annual Meeting Fertilizer Industrial Round Table, 1980 October 28, 29, 30, 1980, Atlanta Biltmore Hotel, Atlanta, Georgia

Wolf, J. B., Fleming, J., \& Batchelor, J. (1985). Fluid Fertilizer Manual (Vol.1-2). National Fertilizer Solution Association, Peoria, Illinois.

\section{Copyrights}

Copyright for this article is retained by the author(s), with first publication rights granted to the journal.

This is an open-access article distributed under the terms and conditions of the Creative Commons Attribution license (http://creativecommons.org/licenses/by/3.0/). 